\title{
Evaluation of Land Cover Changes in Southwestern Lithuania from 1984 to 2018 Using Medium Spatial Resolution Satellite Imagery
}

\author{
Dariusz Gozdowski ${ }^{1 *}$, Jan Žukovskis², Karolina Kaziukonytė3, \\ Artūras Razinkovas-Baziukas ${ }^{3}$ \\ ${ }^{1}$ Department of Biometry, Warsaw University of Life Sciences, Warsaw, Poland \\ ${ }^{2}$ Vytautas Magnus University, Kaunas, Lithuania \\ ${ }^{3}$ Marine Research Institute, Klaipeda University, Lithuania
}

Received: 14 October 2019

Accepted: 4 March 2020

\begin{abstract}
In this study, we assess the land cover changes in southwestern Lithuania from 1984 to 2018. These changes were examined using data derived from Landsat 5, Landsat 8, and Sentinel-2 multispectral images. The study area encompasses the Nemunas Delta, which is affected by river-induced floods leading to seasonal variations in water coverage. The water-covered area was found to be quite stable across the years during the dry seasons, i.e., in summer and early autumn. A significant increase in forested areas was observed during the study period (from $15.1 \%$ to $19.0 \%$ of the total area). During the examined period, the average size of agricultural parcels decreased several times (from approximately 35 ha to approximately $5 \mathrm{ha}$ ), which was caused by the transition from socialist to private ownershipbased agricultural practices in the early 1990s. Almost all changes observed had rather positive environmental impacts (for biodiversity and maintenance of wildlife). Positive impacts included the establishment of several new protected territories between analysed periods. Negative impacts included the construction of wind turbines (approximately 50 in the area of study), which were not present at the beginning of the study period and may negatively affect the natural (agricultural and wetland) landscape of the region.
\end{abstract}

Keywords: remote sensing, land cover change, Landsat, Sentinel-2, Nemunas Delta, floods

*e-mail: dariusz_gozdowski@sggw.pl 


\section{Introduction}

Monitoring of land cover temporal changes is very important because it allows for the evaluation of anthropogenic effects on the environment, e.g., urbanization and deforestation [1,2]. Moreover, this type of monitoring provides a spatial estimation of such natural phenomena as flooding, a succession of natural vegetation and coastline change [3-6]. Land cover monitoring at the regional level over the long-term is also very useful for the assessment of sustainable development of rural areas [7]. In particular, land cover monitoring is important in areas heavily affected by anthropogenic factors. Regional monitoring of land cover is very often based on satellite imagery with medium spatial resolution. The first satellite that delivered such images was Landsat 1, which acquired multispectral images (pixel size $\sim 60 \mathrm{~m}$ ) between 1972 and 1978 [8]. One of the most important satellites for earth observation was Landsat 5, which operated from 1984 to 2003. Landsat 5 was the longest-operating Earth-observing satellite mission in history [9]. The Landsat 5 Thematic Mapper (TM) sensor acquired multispectral images (7 bands from visible light to shortwave infrared) at a spatial resolution of $30 \mathrm{~m}$ and at an interval of 16 days. Currently, the fully operational satellite from the Landsat programme is Landsat 8, which began operation in 2013 and delivers multispectral images (11 bands, most of them at a resolution of $30 \mathrm{~m}$ ) [10]. A very promising source of data for land cover is the Sentinel-2 mission, which consists of two satellites (2A and $2 \mathrm{~B}$ ) that acquire multispectral images at $10 \mathrm{~m}$ resolution [11]. Such satellite data have allowed us to monitor changes in land cover for nearly 50 years. It is very important that the satellite images acquired by both the Landsat and Sentinel programmes (archived and current) are available for free. For many projects that are aimed at evaluating land cover, multispectral satellite data are a very important source of information [12]. One such project is the CORINE land cover (CLC) inventory, which was initiated in 1985 and delivers land cover classification maps for areas covering the whole European Union [13] since 1990. The last update of the CLC project was conducted in 2016-2018 and was based on Sentinel-2 and Landsat-8 data. The minimum mapping unit in CLC is 25 ha and, because of that, smaller objects such as sparsely builtup areas are omitted. The accuracy of CLC is estimated to be at least $85 \%$. Projects similar to CLC comprising large area land cover classification and monitoring long-term changes are conducted at different spatial scales, i.e., regional, continental or worldwide [14].

Land cover classification over large areas using satellite data is performed using supervised or unsupervised methods based on one multispectral satellite image or a multi-temporal set of images [1416]. Supervised classification requires training data that demand in situ knowledge of land cover, at least in some areas of the analyzed region [17]. An unsupervised classification does not require previous knowledge of land cover and, because of that, is easier to implement [18]. Despite the existence of many automated classification methods, the human mind is still one of the finest tools available for the synthesis and analysis of image patterns. Therefore, interpreter expertise is often embedded in land cover classification methods as an auxiliary approach.

The aim of the study was to evaluate the main changes in land cover in southwestern Lithuania between 1984 and 2018 using medium-resolution satellite data. We focused primarily on the changes in the natural environment and land cover types important for the sustainability of the region. Subsequently, the tasks were to evaluate the changes in the spatial coverage of forests, water reservoirs, arable land and built-up areas. This study is especially important because the changes in land cover have not been previously studied over this period. Moreover, the region is very important for ecosystem services because of its location next to estuarine and coastal ecosystems. The study is mainly focused on long-term changes, i.e., between the beginning and the end of the 1984-2018 period.

\section{Material and Methods}

\section{Area of the Study}

The study area is located in southwestern Lithuania (Fig. 1). The region is the southern part of Klaipeda County and is limited geographically by the Curonian Lagoon from the west and the Nemunas River from the south, covering $939.3 \mathrm{~km}^{2}$. Approximately $1 / 3$ of the study area is the Nemunas Delta Regional Park, covering an area of $290 \mathrm{~km}^{2}[19,20]$, which was established in 1992. Spring floods are typical in the park, and in some years, nearly $50 \%$ of the area was flooded. Large parts of the study area are occupied by peatlands, while some of them are exploited. In 1993, Nemunas Delta Regional Park was included in the list of wetlands of international importance by the Ramsar Convention. Later, in 2004-2005, the system of protected areas was supplemented with Natura2000 sites in compliance with the requirements of the EU Birds and Habitats Directives. Agricultural land and forests (mainly coniferous) are located in the eastern and northeastern parts of the study area. The population density in most of the study area is low except in the town of Šilute. The region is very flat, and the study area mostly lies at heights from 0 to 20 metres a.s.l. The best soils, which are characterized by larger silt and clay contents, are located in the southwestern part of the study area, while the worst quality soil (very high sand content) is located in the northeastern part (SoilGrids, https://soilgrids.org) [21]. Because a large part of the study area is flooded annually during the early spring period, it is mainly used as meadows for 


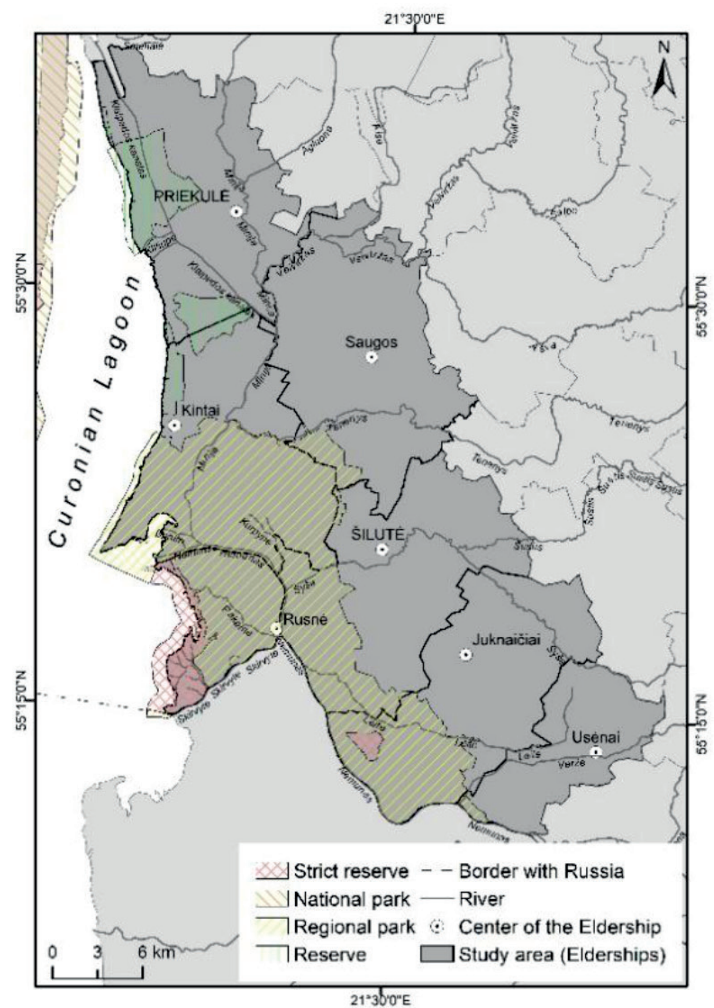

Fig. 1. Study area and its location on the map of Lithuania.

cattle grazing and fodder harvesting. Arable land is located mainly in the southern part of the area (between Šilute and Usènai) as well in the northern part (around Vilkyčiai). The most important changes in arable land coverage and structure started in the early 1990s when private ownership of the farms was re-established.

During the period of 1984-2018, the most significant economic changes in Lithuania, as well in the study area, started, especially in the early 1990 s when private ownership and management in the agricultural sector was re-established [22]. These changes were primarily manifested as the division of large farms into privately owned smaller farms. It was expected that such an economic transition would have an important impact on land cover changes in rural areas.

\section{Methods of Land Cover Evaluation}

The main sources of the data for land cover evaluation were satellite images. Three sources of satellite data were used for the analyses:

- Landsat 5 Thematic Mapper (TM) multispectral sensor, which acquired images from March 1984 to January 2013.

- Landsat 8 Operational Land Imager (OLI) multispectral sensor, which has acquired images since February 2013.

- Sentinel-2 - Sentinel-2A launched in June 2015 and 2B launched in March 2017.

Landsat 5 and 8 have a spatial resolution of $30 \mathrm{~m}$ (pixel $30 \times 30 \mathrm{~m}$ ), while that of Sentinel-2 is $10 \mathrm{~m}$ for

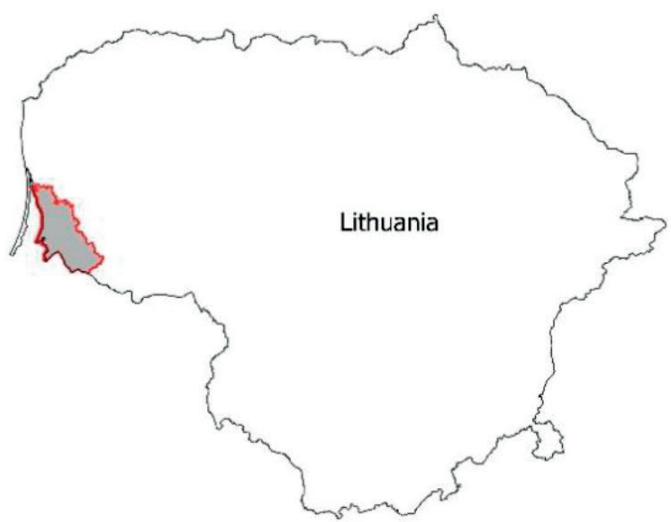

multispectral RGB+NIR (red, green, blue and nearinfrared) data. All images were downloaded from EarthExplorer service: https://earthexplorer.usgs.gov/ [23].

The revisit time for Landsat 5 and 8 is 16 days, while that for Sentinel-2 is approximately 5 days. For the analyses, only images without cloud cover (less than $1 \%$ of clouds) were selected. The main analyses were conducted for the following dates/images:

- 8 April 1984 and 4 June 1984 - Landsat 5 TM (Fig. 2a and 2b)

- 22 April 2018 (Fig. 2c) and 9 June 2018 - Landsat 8 OLI.

- 17 June 2018 - Sentinel-2 (Fig. 2d).

Moreover, additional multi-temporal satellite images were used for better recognition of land cover changes such as forest area, built-up area and water bodies. These images were used mainly for the evaluation of long-term and seasonal water cover and are listed in Table 1.

In the analysis, bands in the visible light range (RGB) and near-infrared (NIR) range were processed via unsupervised clustering using the ISODATA algorithm (pixels were divided into 12 classes). The same approach was applied for satellite images acquired in April (at the beginning of the vegetation period) and June (during intensive growth). This method allowed for better differentiation of land cover types because of the specific seasonal patterns of the various land cover types. 
a)

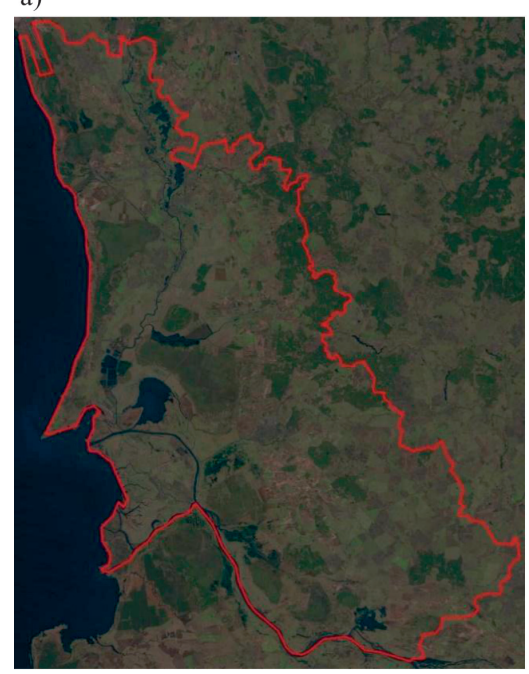

b)

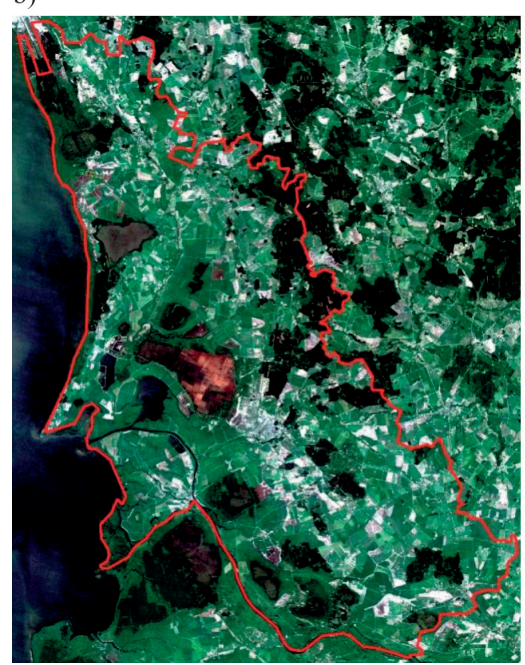

c)

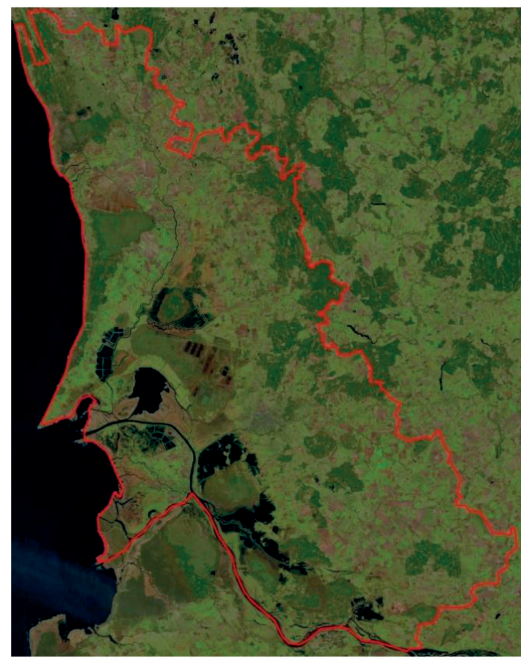

d)

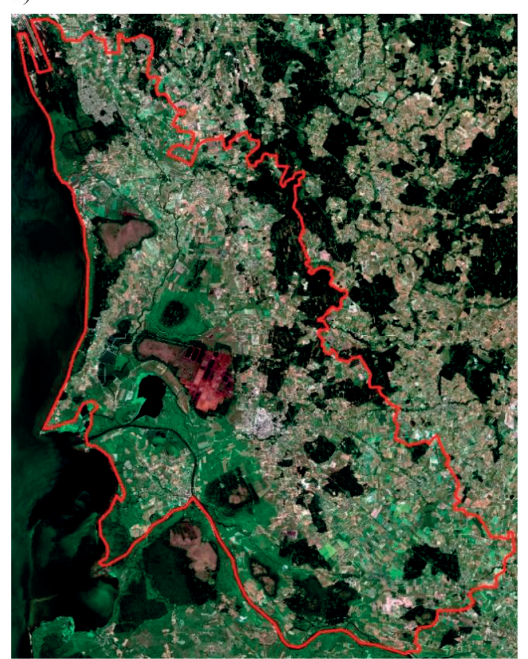

Fig. 2. Satellite images (RGB composite) from a) 8 April 1984 - Landsat 5 TM; b) 4 June 1984 - Landsat 5 TM; c) 22 April 2018 Landsat 8 OLI and d) 17 June 2018 - Sentinel-2.

Most of the forests located in the study area are temperate coniferous forests or mixed coniferous forests. Deciduous forests occur only in a very small area. Because of this, it is quite easy to distinguish forested areas from other land cover types because most of them are evergreen and have high normalized difference vegetation index (NDVI above 0.5 ) values in all seasons. One of the problems is that selected areas of the forests are thinned, and during the first years after thinning, these parts are similar to shrubbery, i.e., are characterized by a low vegetation intensity. If such areas were present within contiguous forested areas, they were classified as forest.

Water features were distinguished using the normalized difference water index (NDWI) [24]. Pixels for which the NDWI was greater than 0 were treated as areas covered by water.

Because of the very low altitude of the study area and seasonal changes in the water level, the area covered by water was very variable, especially in early spring. Water features are quite easy to detect using NDWI based on satellite data, but the accuracy of such delineation can be limited in the following cases:

- where water features are smaller than the satellite pixel size (such a situation very often exists in the case of small rivers, ponds, etc.)

- where water is very shallow and parts of plants are above the water surface (such a situation can exist in wetlands that are temporarily covered by water, especially during the vegetation season)

The final delineation of land cover classes was manually prepared by evaluating the image texture, colours and their patterns using an RGB composite image derived from Landsat 5 for 1984 and a Sentinel-2 image for 2018. Areas in which the land cover types were preliminarily distinguished using unsupervised classification were adjusted or new areas were created in this final stage. Such a method was mainly applied to built-up areas where non-uniform land cover occurs (mixture of buildings, roads and other relatively small 


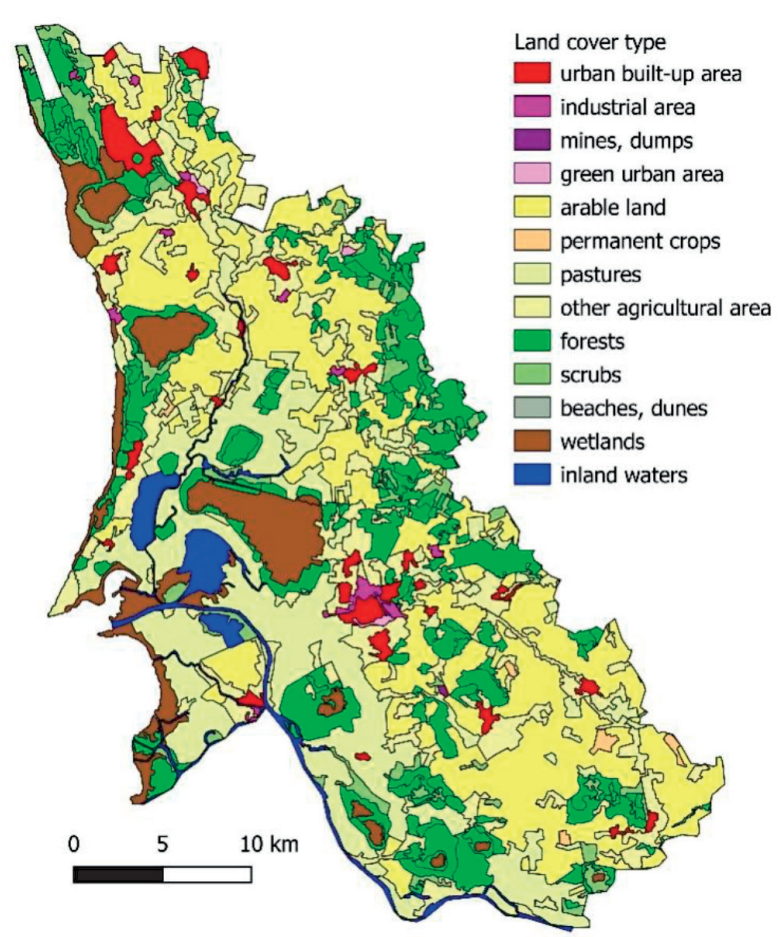

Fig. 3. Types of land cover (level 2) based on the CLC 2018 project for the study area.

objects), the location of wind turbines and deciduous forests, which are not easy to distinguish using unsupervised classification methods. Because of the high spatial resolution of Sentinel-2 images (pixel size $10 \mathrm{~m}$ ), the land cover evaluation for 2018 was more accurate. A summary of the classification methods for each land cover type evaluated in the study is presented in Table 1.
In addition, we used the CORINE land cover 2018 classes as reference data (Fig. 3) [25]. These data were cross-tabulated with land cover classes derived using the ISODATA algorithm [26].

The maps were prepared and spatial analyses were conducted in ArcGIS 10.4 and QGIS 3.4. Non-spatial analyses were conducted in Excel 2016.

\section{Results}

\section{Changes in Water Cover}

The largest area covered by water is usually observed in early spring, i.e., at the end of March or the beginning of April, while the lowest water level is observed in summer and early autumn. Table 1 presents the area of inland water cover estimated using NDWI (values above 0 were treated as water features).

In addition to the dates shown in Table 1, the area of water features was also evaluated in other years. The largest area of water cover was found in the spring of 1985 when the area was $171.46 \mathrm{~km}^{2}(18.25 \%$ of the total study area). In years after 1985 (until 2019), such extensive water-covered areas were not observed. Usually, the area of inland water during early spring was approximately $50-80 \mathrm{~km}^{2}(5.3-8.5 \%$ of the total study area). The obtained data correlate well with the discharge from the Nemunas River (correlation coefficient 0.96 between the water-covered area and 11-day average discharge) (Table 1). During the summer, the area of water features was much smaller and usually covered only approximately $20 \mathrm{~km}^{2}$. However, the extent of the water-covered area did not only depend on rainfall and discharge from the Nemunas River but also on human activities, especially peat exploitation.

Table 1. Area of inland water distinguished based on satellite data on the selected dates.

\begin{tabular}{|c|c|c|c|c|}
\hline Date & Source of data & Area $\left(\mathrm{km}^{2}\right)$ & $\%$ of total land area & $\begin{array}{c}\text { Average discharge from the Nemunas River } \\
\left(\mathrm{m}^{3} / \mathrm{s}\right)^{*}\end{array}$ \\
\hline $1984 / 04 / 08$ & Landsat 5 TM & 79.65 & $8.48 \%$ & 851 \\
\hline $1984 / 06 / 04$ & Landsat 5 TM & 16.09 & $1.71 \%$ & 447 \\
\hline $1985 / 04 / 11$ & Landsat 5 TM & 171.46 & $18.25 \%$ & 810 \\
\hline $2018 / 04 / 22$ & Landsat 8 OLI & 49.54 & $5.27 \%$ & 263 \\
\hline $2018 / 06 / 09$ & Landsat 8 OLI & 18.21 & $1.94 \%$ & 249 \\
\hline $2018 / 06 / 17$ & Sentinel-2 & 20.96 & $2.23 \%$ & 269 \\
\hline $2018 / 10 / 10$ & Sentinel-2 & 31.11 & $3.31 \%$ & 280 \\
\hline $2018 / 10 / 31$ & Landsat 8 OLI & 29.47 & $3.14 \%$ & 562 \\
\hline $2019 / 04 / 02$ & Landsat 8 OLI & 65.87 & $7.01 \%$ & 553 \\
\hline $2019 / 04 / 03$ & Sentinel-2 & 67.84 & $7.22 \%$ & 5 \\
\hline
\end{tabular}

*11-day average, including the 5 days before and 5 days after the date of image acquisition, was calculated from the data obtained from the Lithuanian Hydrometeorological Service. The correlation coefficient between the area of inland water versus the average discharge from the Nemunas River was $0.96(\mathrm{P}<0.001)$. 
Table 2. Satellite image classification methods for the land cover types evaluated in the study.

\begin{tabular}{|c|c|c|}
\hline Land cover type & Method of classification & Additional information \\
\hline Water bodies & $\begin{array}{l}\text { Normalized difference water index } \\
(\mathrm{NDWI}=(\text { green-NIR }) /(\text { green }+\mathrm{NIR})) \text { greater than } \\
0 \text { was treated as water cover. }\end{array}$ & $\begin{array}{l}\text { Change in water cover between } 1984 \text { and } 2018 \text { was based on } \\
\text { satellite data from June when there are no floods. }\end{array}$ \\
\hline Forests & $\begin{array}{l}\text { High value of normalized difference vegetation } \\
\text { index (NDVI above } 0.5 \text { ) in early spring as well } \\
\text { during summer was treated as deciduous forests. }\end{array}$ & $\begin{array}{l}\text { Areas of lower NDVI found within contiguous forested area } \\
\text { were treated as forest. Moreover, deciduous forests were } \\
\text { distinguished using RGB satellite image photo interpretation } \\
\text { based on texture, colours and patterns. }\end{array}$ \\
\hline Built-up area & $\begin{array}{c}\text { Preliminary division into various land cover } \\
\text { classes using the unsupervised ISODATA } \\
\text { algorithm. }\end{array}$ & $\begin{array}{l}\text { Final classification and detection of wind turbine locations } \\
\text { using RGB satellite image photo interpretation based on } \\
\text { texture, colours, shadows and patterns. }\end{array}$ \\
\hline $\begin{array}{l}\text { Agricultural } \\
\text { land }\end{array}$ & $\begin{array}{l}\text { Not classified because of high classification } \\
\text { uncertainty. }\end{array}$ & $\begin{array}{l}\text { Delineation of individual agricultural parcels for selected } \\
\text { parts of the study area based on RGB satellite image photo } \\
\text { interpretation based on texture, colours and patterns. }\end{array}$ \\
\hline
\end{tabular}

During the summer of 2018, approximately $1 \mathrm{~km}^{2}$ of water cover was observed in the large peatland located next to Šilutè despite the low precipitation. Most of the differences between 1984 and 2018 in water cover during summer (Fig. 4, Table 3) were probably because of anthropological reasons associated with land reclamation. One of the long-term natural changes in the 1984-2018 period was the creation of an island with an area of approximately 20 ha in the Nemunas River mouth, which could be attributed to sediment accumulation (Fig. 5).

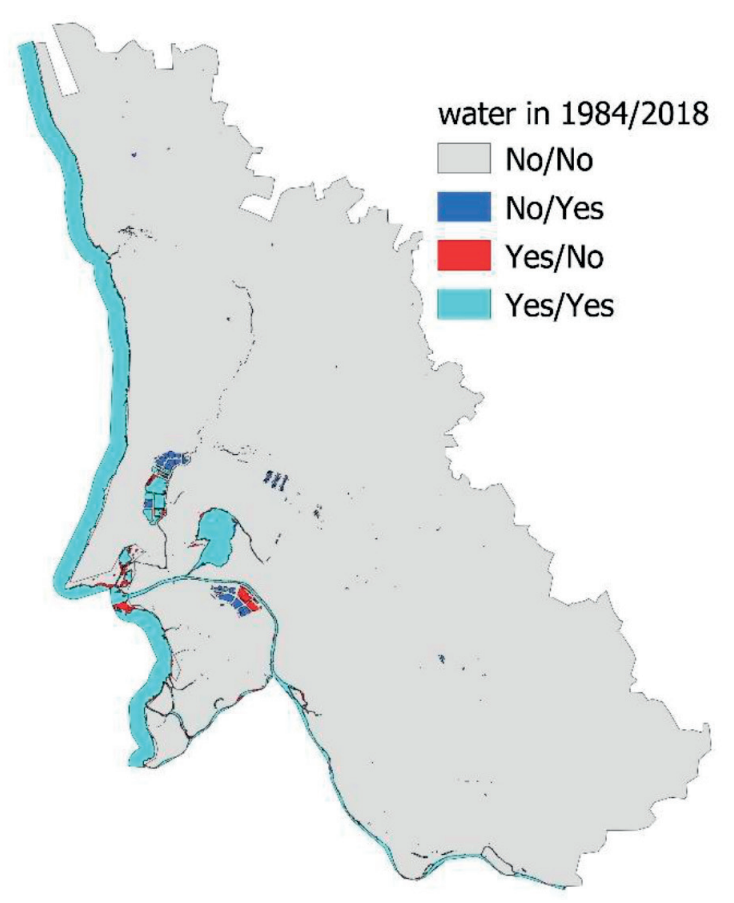

Fig. 4. Water cover on 1984/06/04 and 2018/06/09 based on satellite imagery.

$\mathrm{No} / \mathrm{No}$ - areas without water in both years, No/Yes - areas with water in only 2018, Yes /No - areas with water in only 1984; Yes/ Yes - areas with water in both years

\section{Changes in the Forested Area}

During 1984-2018, forested areas increased approximately by $36.8 \mathrm{~km}^{2}$ (from $141.9 \mathrm{~km}^{2}$ to $178.7 \mathrm{~km}^{2}$ ) (Table 4). The forests mainly increased because of the natural development of areas located

a)

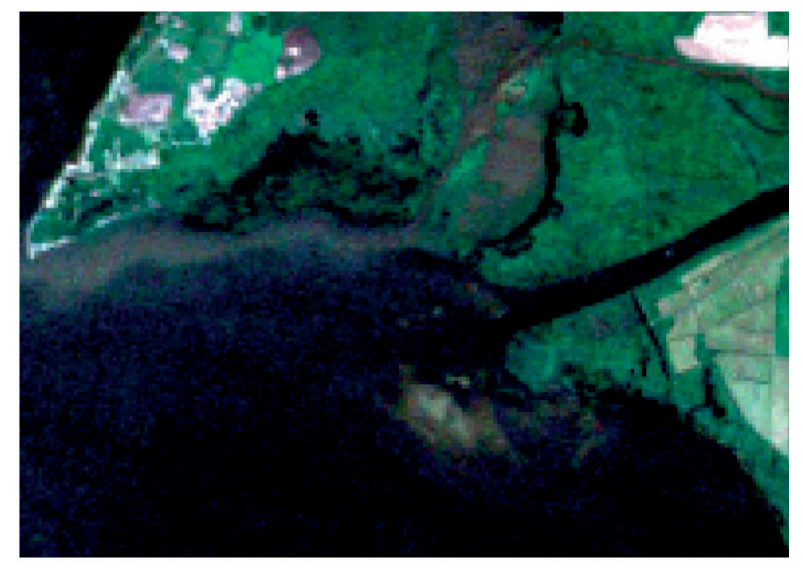

b)

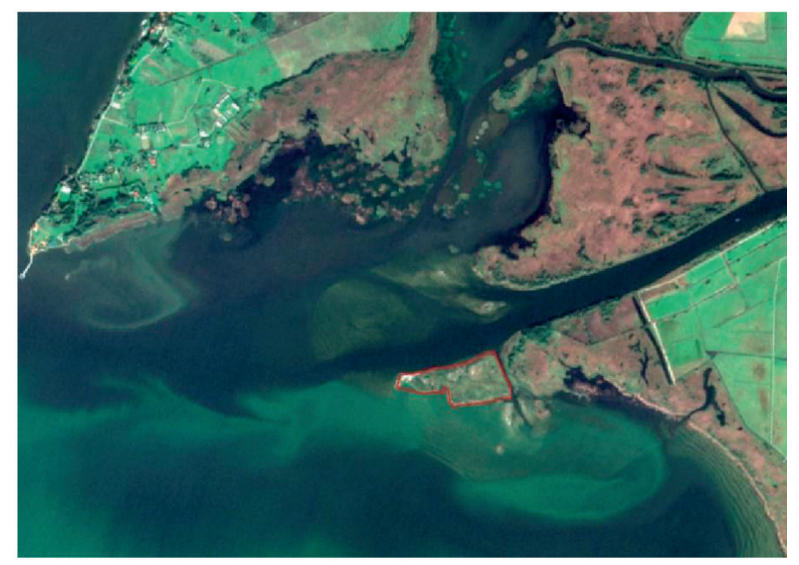

Fig. 5. Satellite image of the Nemunas River mouth on 1984/06/04 (A - Landsat 5 TM) and 2018/06/09 (B - Sentinel-2) with the new islands created by sediments marked by a red border. 
Table 3. Inland water areas in June 1984 and 2018 in the study area.

\begin{tabular}{|c|c|c|c|c|}
\hline \multirow{2}{*}{} & \multicolumn{3}{|c|}{ Water covered area in $1984\left(\mathrm{~km}^{2}\right)$} \\
\cline { 3 - 5 } & & No & Yes & Total \\
\hline \multirow{3}{*}{ Water covered area in $2018\left(\mathrm{~km}^{2}\right)$} & No & $918.5(97.8 \%)$ & $2.6(0.3 \%)$ & $921.1(98.1 \%)$ \\
\cline { 2 - 5 } & Yes & $4.0(0.4 \%)$ & $14.2(1.5 \%)$ & $18.2(1.9 \%)$ \\
\cline { 2 - 5 } & Total & $922.5(98.2 \%)$ & $16.8(1.8 \%)$ & $939.3(100.0 \%)$ \\
\hline
\end{tabular}

Table 4. Forest areas in 1984 and 2018 in the study area.

\begin{tabular}{|c|c|c|c|c|}
\hline \multirow{2}{*}{\multicolumn{2}{|c|}{}} & \multicolumn{3}{|c|}{ Forest area in 1984 $\left(\mathrm{km}^{2}\right)$} \\
\cline { 3 - 5 } & No & $758.3(80.7 \%)$ & Yes & Total \\
\hline \multirow{3}{*}{ Forest area in $2018\left(\mathrm{~km}^{2}\right)$} & Yes & $39.1(4.2 \%)$ & $139.5(14.9 \%)$ & $1780.6(81.0 \%)$ \\
\cline { 2 - 5 } & Total & $797.4(84.9 \%)$ & $141.9(15.1 \%)$ & $939.3(100.0 \%)$ \\
\cline { 2 - 5 } & & &
\end{tabular}

next to peatlands and other areas that are not intensively used. Large areas of shrubbery were transformed into a forest. Moreover, some parts of agricultural land were transformed into a forest, especially those located next to large forested areas, which were most frequently dominated by sandy soils (https://soilgrids.org). Most of the forests that existed in 1984 were still forest in 2018, and only $2.3 \mathrm{~km}^{2}$ of the forest was transformed into other types of land cover. Fig. 6 presents the forested areas in 1984 and 2018.

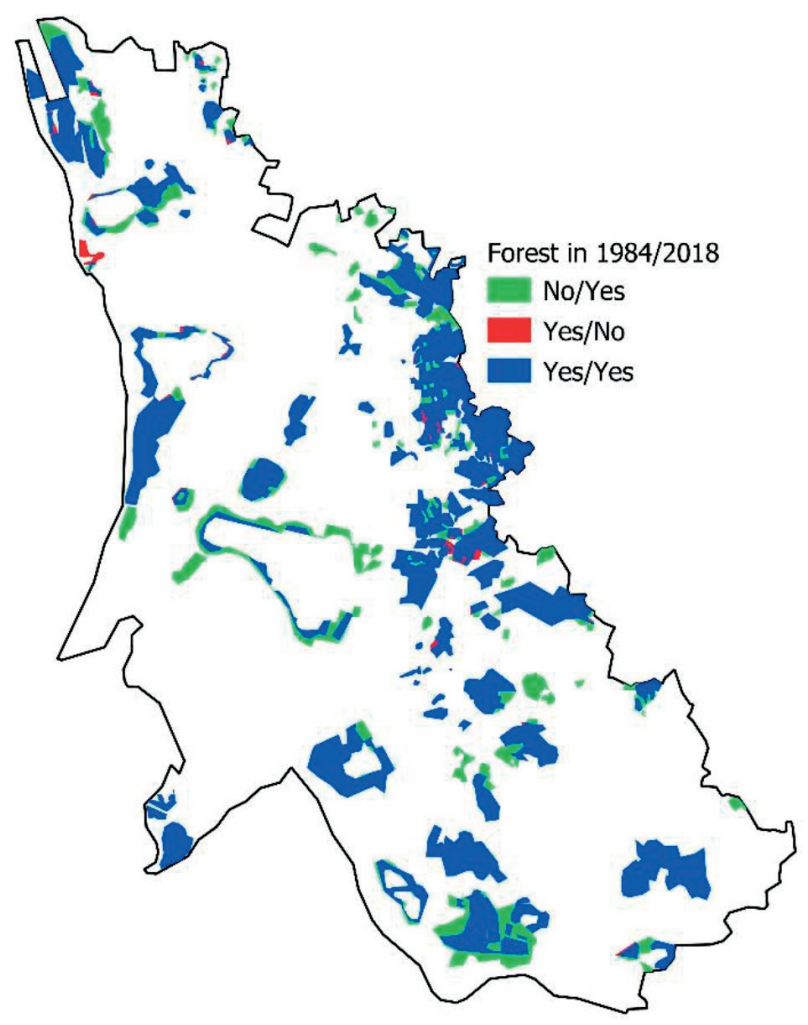

Fig. 6. Forest areas in 1984 and 2018 in the study area.

\section{Changes in Agricultural Land}

Large crop fields were divided into smaller parcels between 1984 and 2018. The average size of arable land parcels in 1984 was estimated at approximately 35 ha based on a sample consisting of several dozen parcels delineated using Landsat 5 imagery. In 2018, the average parcel size was much smaller, and it was estimated to be only approximately 5 ha. The borders of the agricultural parcels for selected parts (next to the town of Juknaičiai) of the study area in 1984 and 2018 are presented in Fig. 7.

\section{Changes in Built-Up Areas}

The area of this land cover type in 1984 was estimated at 4176 ha, which was $4.45 \%$ of the total study area. The changes in the built-up area from 1984-2018 were small, and the increase in built-up area was estimated at 155 ha. This result means that the total built-up area in 2018 was approximately 4331 ha (4.61\% of the total study area). The built-up areas in 1984 and 2018 are presented in Fig. 8.

An important change in the landscape of rural areas is the construction of wind turbines, which were not present at the beginning of the study period. In 2018, the number of wind turbines was estimated at 48. This assessment was based on the photointerpretation of Sentinel-2 RGB imagery, based on the presence of specific shadows and bare soil around each turbine.

\section{Discussion}

Monitoring long-term land cover change is important for evaluating environmental sustainability at the regional scale. Multispectral satellite images (visible 
a)

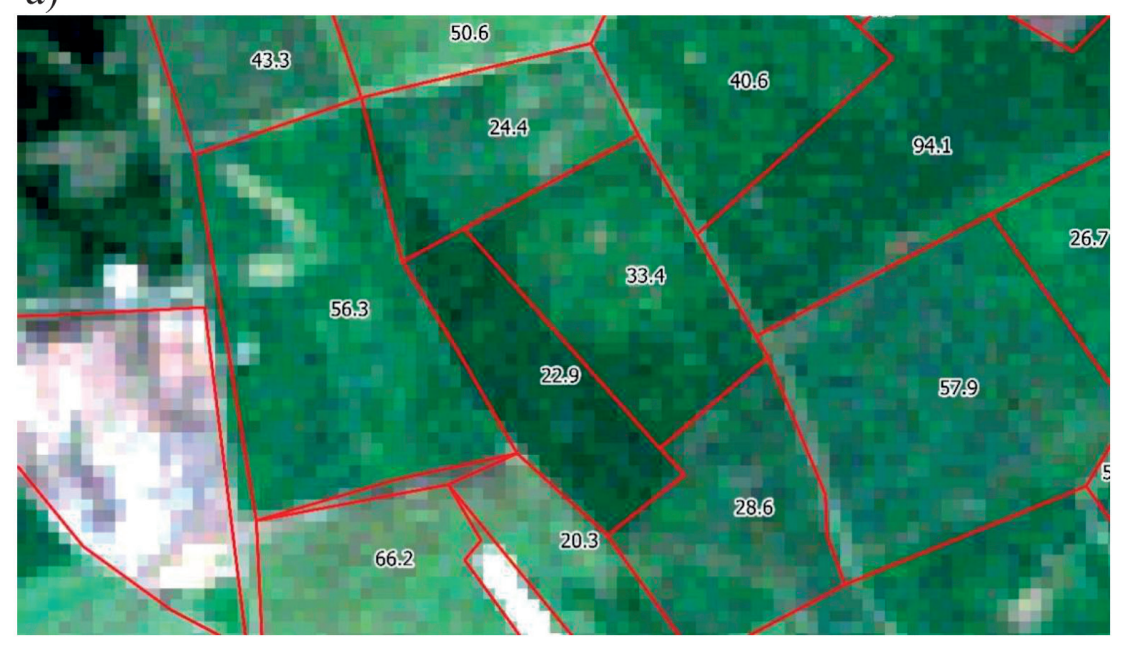

b)

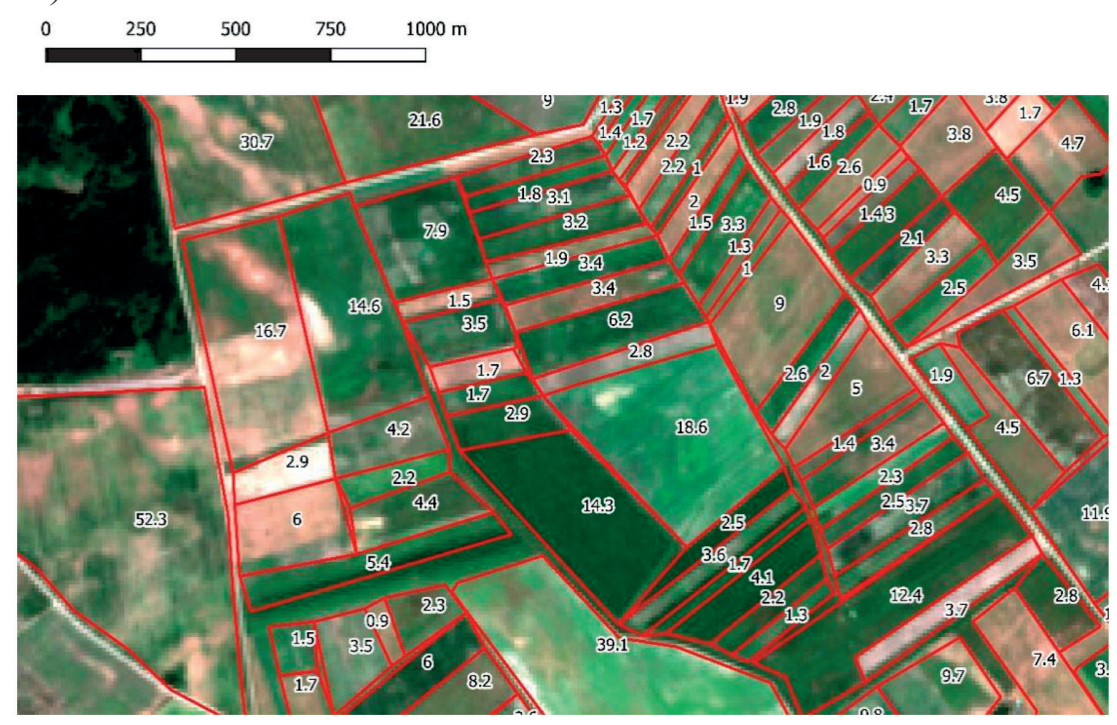

Fig. 7. Borders and area (in ha) of agricultural parcels in a) 1984 and b) 2018 for selected parts of the study area (next to the town of Juknaičiai).

light - RGB and near-infrared - NIR) are very important sources of information to make such assessments [27]. The earliest sources useful for this task are the Landsat satellites, which were available beginning in 1972 [8]. Unfortunately, the first three Landsat satellites acquired multispectral images of lower resolution (pixel size 60-80 m). However, from 1982, when Landsat 4 was launched, multispectral images became more detailed (30 m resolution), enabling better accuracy of land cover classification. One of the most important advantages of Landsat imagery is the availability of historical data on a free-of-charge basis [28]. This imagery allows for retrospective analyses using images dated several decades back. One of the very important disadvantages of Landsat satellites is the long revisiting time of 16 days, which is an important drawback in areas such as western Lithuania, where cloud cover was detected in $2 / 3$ of the available images. Fully free cloud scenes are very rare, and for the study area, only approximately $20 \%$ of the images are available, which means that only 2-5 images per year are suitable for land cover classification. Most of the images obtained in winter were not suitable because of the snow cover. In this study, the most useful images were obtained in the summer period, when the river water level was low and lowlands were not flooded. Better land cover classification is possible when using multi-temporal images. However, we also found good use of satellitederived data for the evaluation of seasonal changes in water coverage, which exhibited high variability because of the extensive early spring floods. Moreover, satellite images obtained in early spring or late autumn were useful for the recognition of evergreen forested areas, which represent both coniferous and mixed forests in this region. Despite the extensive analysis of multispectral images acquired in different seasons, it was not possible to assess all land cover types with satisfactory reliability. 


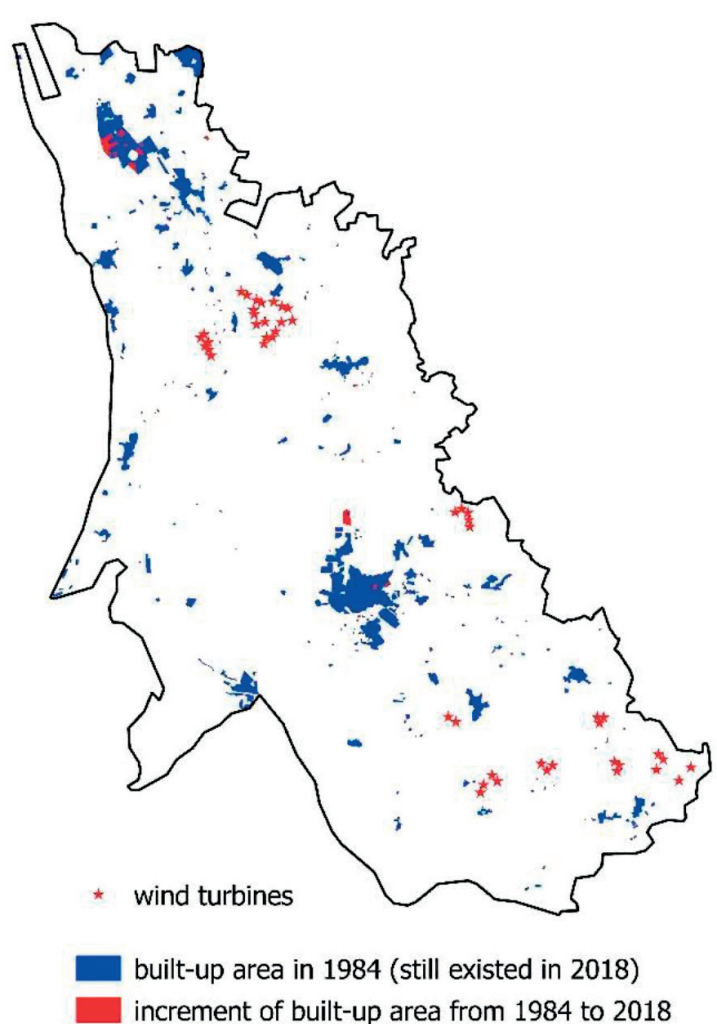

Fig. 8. Built-up area in 1984 and 2018 in the study area.

Hence, this study focused on only the selected land cover types for which land cover classification was quite easy and accurate.

The areas of arable land and other types of agricultural land use were not estimated in the study because of the difficulties in classification. The main reason for this difficulty was the differences in the vegetation periods for the different crop types. Some crops are sown very late (e.g., maize or some vegetables), while others are harvested very early (e.g., winter rapeseed). Because of the variability in the temporal patterns of reflectance associated with different crop types, it was difficult to classify agricultural areas unambiguously.

Because of the insufficient spatial resolution of satellite images obtained in 1984, it was not possible to distinguish small individual buildings or buildings in sparse built-up areas dominated by green vegetation. Only dense built-up areas were taken into consideration in this study. Moreover, housing development and industrial built-up areas were treated together rather than distinguished into different classes.

One of the easiest land cover types to detect is water. However, the area of water cover can be underestimated because of the moderate pixel size of satellite data used for the analyses. The area of water features estimated for almost the same date (one day difference) in early April 2019 using Sentinel-2 (pixel size $10 \mathrm{~m}$ ) was $2 \mathrm{~km}^{2}$ higher than the results based on Landsat 8 data (pixel size $30 \mathrm{~m}$ ). This difference was mainly due to the use of higher resolution data (smaller pixels) which allowed us to distinguish water features such as small rivers and ponds. Most likely, when using very high-resolution satellite images (e.g., pixel size $\sim 1 \mathrm{~m}$ ), the water cover area can be more consistent and slightly larger in comparison to the results in this study.

In this study, we observed very high seasonal variability in water cover. The largest extent of the water-covered area was observed in early spring of 1985. The water cover during this period was approximately 10 times larger than the typical water coverage in summer. In the satellite images acquired after this time, the water cover area was usually much smaller. In general, the water area delineated from the satellite images in early spring was approximately 3 times larger than that in summer. Such a pattern will probably be sustained in the future with some shift from spring to winter following the climatic projections for precipitation (stable in the spring and slight increase during the winter) [29].

Changes in water area during summer are dependent mainly on anthropogenic activities such as peat exploitation. In addition to the results presented in Table 1, water cover was assessed in 1999, 2004 and 2017 to compare the water levels between years. The total area in summer was very stable across years, but some water features changed. Nearly $40 \%$ of the study area is covered by summer or winter polders to protect settlements or agricultural lands. Most of these polders still have functioning pumping stations that regulate the water level inside the polders. After regaining independence, some pumping stations in the Lithuanian part of the Nemunas Delta became defunct, leading to the renaturalization of these areas [19].

One of the most important land cover changes in the study area between 1984 and 2018 was the increase in forested areas. The increase was mainly caused by the transition of scrub-shrub habitats to forests. This transition was mainly observed in natural areas situated next to peatlands. Moreover, some marginal agricultural land was reforested. In general, it could be considered as a positive change considering the comparatively low percentage of forests in the delta area (in 2018, it was approximately 19\%).

One of the most important changes in the agricultural areas was related to the transition in the early 1990s when private ownership of farms was reestablished [22]. After the transition, the average size of agricultural parcels decreased by several times. Moreover, in agricultural areas, approximately 50 wind turbines were built, which has changed the landscape in some parts of the study area. The wind turbines are mainly located in agricultural land in the southern (around Usènai) and northern (between Vilkyčiai and Saugos) parts of the study area. The wind turbines occupy a relatively small area (approximately several ha in total) but could have a significant impact on the agricultural landscape of the region. This impact is mainly because of the very large height (100-150 m) and low but continuous noise that is generated. 
Evaluation of changes in land cover in such regions as southwestern Lithuania, located next to the coast of the Baltic Sea is especially significant because of the land use relationship to the marine ans estuarine eutrophication and biodiversity in coastal environments [30]. The increase in natural areas such as forests is contributing to both the biodiversity and surface water quality. Moreover, changes in land cover have a significant impact on ecosystem services, which are important in areas located next to estuarine and coastal ecosystems [31]. The natural variability of such regions impacts the supply of such ecosystem services as tourism and recreation as well as the maintenance of wildlife.

\section{Conclusions}

Medium-resolution satellite data allowed us to estimate the changes in selected land cover types in southwestern Lithuania from 1984-2018. The watercovered area was characterized by very sharp seasonal differences because of early spring floods, which occur every year, and the differences in water coverage between the analyzed images were consistent with the average observed discharge from the Nemunas River. The area of water during summer remained quite stable across the years. During the study period, a substantial increase in forested areas was observed. The builtup area increased slightly but remained quite stable; however, 50 new wind turbines were constructed in recent years.

Not all types of land cover could be distinguished using medium-resolution satellite data. The current development of satellite sensors and small satellite platforms will allow better accuracy of land cover classification to be obtained in the near future and could be used for a much more detailed assessment of land cover types.

\section{Acknowledgements}

The preparation of this paper was supported by funding from the European Social Fund (project No 09.3.3-LMT-K-712-01-0178) under a grant agreement with the Research Council of Lithuania (LMTLT). We would also like to thank Jolanta Vilkevičiūte, Lina Marcinkevičiūtè and Zita R. Gasiūnaitè for their invaluable comments and constructive collaboration in preparing the article.

\section{Conflict of Interest}

The authors declare no conflicts of interest.

\section{References}

1. OLOFSSON P., HOLDEN C.E., BULLOCK E.L., WOODCOCK C.E. Time series analysis of satellite data reveals continuous deforestation of New England since the 1980s. Environmental Research Letters, 11 (6), 064002, 2016.

2. OLIVIA S., BOE-GIBSON G., STITCHBURY G., BRABYN L., GIBSON J. Urban land expansion in Indonesia 1992-2012: evidence from satellite-detected luminosity. Australian Journal of Agricultural and Resource Economics, 62 (3), 438, 2018.

3. FRANCI F., BITELLI G., MANDANICI E., HADJIMITSIS D., AGAPIOU A. Satellite remote sensing and GIS-based multi-criteria analysis for flood hazard mapping. Natural Hazards, 83 (1), 31, 2016.

4. MISRA A., BALAJI R. A study on the shoreline changes and Land-use/land-cover along the South Gujarat coastline. Procedia Engineering, 116, 381, 2015.

5. JASKUŁA J., SOJKA M. Assessing Spectral Indices for Detecting Vegetative Overgrowth of Reservoirs. Polish Journal of Environmental Studies, 28 (6), 2019.

6. JULIEV M., PULATOV A., FUCHS S., HÜBL J. Analysis of Land Use Land Cover Change Detection of Bostanlik District, Uzbekistan. Polish Journal of Environmental Studies, 28 (5), 2019.

7. LAMBIN E.F., TURNER B.L., GEIST H.J., AGBOLA S.B., ANGELSEN A., BRUCE J.W., COOMES O.T., DIRZO R., FISCHER G., FOLKE C., GEORGE P.S., HOMEWOOD K., IMBERNON J., LEEMANS R., LI X., MORAN E.F., MORTIMORE M., RAMAKRISHNAN P.S., RICHARDS J.F., SKANE H., STEFFEN W., STONE G.D., SVEDIN U., VELDKAMP T.A., VOGEL C. GEORGE, P. The causes of land-use and land-cover change: moving beyond the myths. Global Environmental Change, 11 (4), 261, 2001.

8. WULDER M.A., LOVELAND T.R., ROY D.P., CRAWFORD C.J., MASEK J.G., WOODCOCK C.E., ALLEN R.G., ANDERSON M.C., BELWARD A.S., COHEN W.B., DWYER J., ERB A., GAO F., GRIFFITHS P., HELDER D., HERMOSILLA T., HIPPLE J.D., HOSTERT P., HUGHES M.J. , HUNTINGTON J., JOHNSON D.M., KENNEDY R., KILIC A., LI Z., LYMBURNER L., MCCORKEL J., PAHLEVAN N., SCAMBOS T.A., SCHAAF C., SCHOTT J.R., SHENG Y., STOREY J., VERMOTE E., VOGELMANN J., WHITE J.C., WYNNE R.H., ZHU Z. Current status of Landsat program, science, and applications. Remote Sensing of Environment, 225, 127, 2019.

9. BELWARD A.S., SKØIEN J.O. Who launched what, when and why; trends in global land-cover observation capacity from civilian earth observation satellites. ISPRS Journal of Photogrammetry and Remote Sensing, 103, 115, 2015.

10. POURSANIDIS D., CHRYSOULAKIS N., MITRAKA Z. Landsat 8 vs. Landsat 5: A comparison based on urban and peri-urban land cover mapping. International Journal of Applied Earth Observation and Geoinformation, 35, 259, 2015.

11. ERINJERY J.J., SINGH M., KENT R. Mapping and assessment of vegetation types in the tropical rainforests of the Western Ghats using multispectral Sentinel-2 and SAR Sentinel-1 satellite imagery. Remote Sensing of Environment, 216, 345, 2018. 
12. HANSEN M.C., LOVELAND T.R. A review of large area monitoring of land cover change using Landsat data. Remote Sensing of Environment, 122, 66, 2012.

13. FERANEC J., SOUKUP T., HAZEU G., JAFFRAIN G. (Eds.). European landscape dynamics: CORINE land cover data. CRC Press, 2016.

14. FRANKLIN S.E., WULDER M.A. Remote sensing methods in medium spatial resolution satellite data land cover classification of large areas. Progress in Physical Geography, 26 (2), 173, 2002.

15. PHIRI D., MORGENROTH J. Developments in Landsat land cover classification methods: A review. Remote Sensing, 9 (9), 967, 2017.

16. ZAIDI S.M., AKBARI A., ABU SAMAH A., KONG N.S., GISEN A., ISABELLA J. Landsat-5 Time Series Analysis for Land Use/Land Cover Change Detection Using NDVI and Semi-Supervised Classification Techniques. Polish Journal of Environmental Studies, 26 (6), 2017.

17. MARCAL A.R.S., BORGES J.S., GOMES J.A., PINTO DA COSTA J.F. Land cover update by supervised classification of segmented ASTER images. International Journal of Remote Sensing, 26 (7), 1347, 2005.

18. CANTY M.J., NIELSEN, A.A. Visualization and unsupervised classification of changes in multispectral satellite imagery. International Journal of Remote Sensing, 27 (18), 3961, 2006

19. LUKIANAS, A., VAIKASAS S., MALISAUSKAS A.P. Water management tasks in the summer polders of the Nemunas Lowland. Irrigation and Drainage, 55 (2), 145, 2006.

20. NEMUNO DELTOS REGIONINIS PARKAS Available online: http://www.nemunodelta.lt/ (accessed on 10 October 2019)

21. HENGL T., DE JESUS J.M., HEUVELINK G.B., GONZALEZ M.R., KILIBARDA M., BLAGOTIĆ A., SHANGGUAN W., WRIGHT M.N., GENG X., BAUERMARSCHALLINGER B., GUEVARA M.A., VARGAS R., MACMILLAN R.A., BATJES N.H., LEENAARS J.G.B., RIBEIRO E., WHEELER I., MANTEL S., KEMPEN B. Soil Grids $250 \mathrm{~m}$ : Global gridded soil information based on machine learning. PLOS ONE, 12 (2), e0169748 1-40, 2017.

22. DAVIS J.R. Understanding the process of decollectivisation and agricultural privatisation in transition economies: The distribution of collective and state farm assets in Latvia and Lithuania. Europe-Asia Studies, 49 (8), 1409, 1997.

23. USGS, EarthExplorer, Available online: https:// earthexplorer.usgs.gov/ (accessed on 10 October 2019)

24. MCFEETERS S.K. The use of the Normalized Difference Water Index (NDWI) in the delineation of open water features. International Journal of Remote Sensing, 17 (7), $1425,1996$.

25. Copernicus Programme, CORINE Land Cover. Available online: https://land.copernicus.eu/pan-european/corineland-cover (accessed on 2 March 2020)

26. BALL G.H., HALL D.J., ISODATA, a novel method of data analysis and pattern classification. Stanford Research Institute Menlo Park CA, NTIS No. AD 699616, 1965.

27. ACHARYA T., YANG I., LEE D. Land cover classification using a Kompsat-3a multi-spectral satellite image. Applied Sciences, 6 (11), 371, 2016.

28. WOODCOCK C.E., ALLEN R., ANDERSON M., BELWARD A., BINDSCHADLER R., COHEN W., GAO F., GOWARD S.N, HELDER D., HELMER E., NEMANI R., OREOPOULOS L., SCHOTT J., THENKABAIL P.S., VERMOTE E.F., VOGELMANN J., WULDER M.A. Free access to Landsat imagery. Science, 320 (5879), 1011, 2008.

29. JAAGUS J., BRIEDE A., RIMKUS E., SEPP M. Changes in precipitation regime in the Baltic countries in 1966-2015. Theoretical and Applied Climatology, 131 (1-2), 433, 2018.

30. KERN K. Governance for sustainable development in the Baltic Sea region. Journal of Baltic Studies, 42 (1), 21, 2011.

31. BARBIER E.B., HACKER S.D., KENNEDY C., KOCH, E.W., STIER A.C., SILLIMAN B.R. The value of estuarine and coastal ecosystem services. Ecological Monographs, 8 1 (2), 169, 2011. 